Cinémas

Revue d'études cinématographiques

Journal of Film Studies

\title{
Orphée au Brésil
}

L'imaginaire européen à l'épreuve de la danse

\section{Johanne Villeneuve}

Volume 15, numéro 1, automne 2004

Entre l'Europe et les Amériques

URI : https://id.erudit.org/iderudit/011661ar

DOI : https://doi.org/10.7202/011661ar

Aller au sommaire du numéro

Éditeur(s)

Cinémas

ISSN

1181-6945 (imprimé)

1705-6500 (numérique)

Découvrir la revue

Citer cet article

Villeneuve, J. (2004). Orphée au Brésil : l'imaginaire européen à l'épreuve de la danse. Cinémas, 15(1), 105-122. https://doi.org/10.7202/011661ar

\section{Résumé de l'article}

L'article qui suit propose une étude du film Orfeu Negro de Marcel Camus (1959) et une réflexion théorique sur le rapport entre cinéma et oralité. Film de fiction inspiré par une certaine ethnographie, Orfeu Negro transpose le mythe d'Orphée dans un Brésil aussi actuel qu'intemporel. À travers sa rencontre avec le Brésil, ses acteurs, musiciens et danseurs, Camus révèle le caractère orphique d'un cinéma dansé et chanté ; il exalte le carnaval, le corps et le chamanisme ; il renoue avec le caractère enchanté d'une culture que nous nous proposons de décrire ici et qui contraste avec la culture européenne à laquelle le réalisateur appartient. 


\title{
Orphée au Brésil. L'imaginaire européen à l'épreuve de la danse ${ }^{1}$
}

\author{
Johanne Villeneuve
}

\section{RÉSUMÉ}

L'article qui suit propose une étude du film Orfeu Negro de Marcel Camus (1959) et une réflexion théorique sur le rapport entre cinéma et oralité. Film de fiction inspiré par une certaine ethnographie, Orfeu Negro transpose le mythe d'Orphée dans un Brésil aussi actuel qu'intemporel. À travers sa rencontre avec le Brésil, ses acteurs, musiciens et danseurs, Camus révèle le caractère orphique d'un cinéma dansé et chanté; il exalte le carnaval, le corps et le chamanisme; il renoue avec le caractère enchanté d'une culture que nous nous proposons de décrire ici et qui contraste avec la culture européenne à laquelle le réalisateur appartient.

\section{ABSTRACT}

This article presents an analysis of Marcel Camus's Orfeu Negro (1959) and a theoretical investigation of the relation between cinema and orality. Inspired by ethnographic studies, Orfeu Negro is a fiction film that transposes the myth of Orpheus to a contemporary yet timeless Brazil. Through his encounter with Brazilian actors, musicians, and dancers, Camus reveals the Orphean nature of a type of cinema that is danced and sung; he praises the carnival, the body and shamanism; he revives the enchanted nature of a culture that is here described as contrasting with the director's own European culture. 
À la fin des années 1950, parallèlement à la Nouvelle Vague, Marcel Camus entreprend au Brésil la réalisation de son film Orfeu Negro ${ }^{2}$, d'après une pièce de théâtre écrite par Vinicius de Moraes. Le premier film de Camus à titre de réalisateur abordait la question du colonialisme (Mort en fraude, 1957); ceux qui suivront seront bientôt taxés d'exotisme. Entre ces deux pôles, Orfeu Negro témoigne d'une tension aussi productive que formidable entre une lecture ethnographique (qui pose l'exigence d'une certaine vérité dans la rencontre de l'altérité) et une posture idéologique (qui célèbre la différence en l'idéalisant, voire en la mythifiant).

La relation entre les deux visées, celle de la vérité et celle de l'idéal, paraît indénouable. Cela vient de ce que le cinéaste cherche à effacer sa présence au profit de l'exposition d'un monde tel quil senvisage lui-même, tout en maintenant pour soi, subjectivement, une vision utopiste de ce monde. Le regard ethnographique de Camus revendique en effet quelque chose au nom de l'altérité, dont il cherche à mettre en valeur l'originalité et la réalité nue, mais, ce faisant, il ne peut qu'affirmer son propre désir. C'est là sans doute le paradoxe qui accompagne le travail de tout ethnographe, comme n'ont cessé de le rappeler de nombreuses études sur le sujet ${ }^{3}$. Le savoir que l'ethnographie met au jour concernant telle ou telle culture pose toujours le problème d'un sujet de connaissance; il n'est toujours qu'un savoir au regard d'un sujet différent. Aussi Camus s'adresse-t-il d'abord et avant tout à un public européen quand il invente un Brésil depuis le creuset d'une autre culture.

Ce qui retient toutefois mon attention dans ce cas particulier est que ce film n'est justement pas un film «ethnographique», et qu'il dépasse sa propre posture idéologique en se laissant entrâ̂ner par une forme particulièrement ancienne d'exultation poétique. Ici, l'exigence de vérité coïncide avec la forme idéalisante pour produire un effet qui est le contraire de la distanciation ethnographique sans être pour autant tributaire du caractère subjectif de l'œuvre. De la vérité des corps filmés surgit un paysage idéalisé, un monde tel qu'envisagé en lui-même, avec sa paysagéité vivante, en tant qu'exultation poétique. La geste des acteurs s'empare en quelque sorte du dessein initial du réalisa- 
teur. Le carnaval de Rio semble dicter son propre film. Et si, en apparence, une tension demeure entre les deux visées mentionnées plus haut, elle se résout dans l'événementialité du film, qui fait advenir ce que Camus ne pouvait prévoir dans son scénario.

Croyant transposer le mythe d'Orphée dans un Brésil contemporain, à la fois urbain et carnavalisé, éternel et anachronique, Camus révèle le caractère orphique d'un cinéma dansé et chanté; il fait du médium filmique l'instrument de prédilection du carnaval, un véritable "franchisseur de frontières». Or, il s'agit justement là d'une définition qu'on peut donner d'Orphée: celui qui traverse les mondes ${ }^{4}$.

\section{La culture enchantée}

La musique d'Antonio Carlos Jobim et de Luis Bonfa pénètre les images de Orfeu Negro du début à la fin. Ni simple accompagnatrice ni appui narratif, elle constitue à la fois l'enveloppe formelle à l'intérieur de laquelle se déploie le rythme du film son milieu - et le noyau isotopique d'où partent en volutes les thèmes abordés: l'amour, la mort, la jalousie, l'espérance et l'allégresse. Rien n'échappe à la musique dont le propre, ironiquement, consiste à s'échapper du cour des hommes; elle n'appartient à personne mais consacre entre les êtres les liens les plus forts de l'envoûtement. L'emprise de la musique apparaît dans ce film à ce point déterminante qu'elle représente dans l'univers du héros Orfeu l'autorité ultime capable de «faire lever le jour». Jouant de sa guitare et chantant du plus haut sommet de la ville, Orfeu fait advenir, à l'aurore, la toute-puissance de l'astre solaire. Le geste et la voix du musicien inaugurent ainsi quotidiennement la possibilité même du vivant. Cette rare emprise est pourtant caractéristique de ce que j'aimerais appeler une "culture enchantée", tributaire des plus anciens modes de médiation orale ${ }^{5}$.

Issue de la tradition orale, la culture enchantée est portée par le chant. Celui-ci constitue son milieu propre. C'est avec cette culture que Camus renoue à travers son film, confiant à des danseurs et des chanteurs plus qu'à des acteurs le soin d'en faire revivre le mythe. Ainsi, l'autorité même du réalisateur 
s'émousse, comme se marginalisent les traces d'une langue scénaristique au profit des performances kinesthésiques et musicales. L'efficacité de la performance est redoublée par l'usage de la langue portugaise, le scénario ayant été traduit du français vers cette langue. Supposer que cet usage réponde seulement à l'impératif de vraisemblance ou aux nécessités de la coproduction serait réducteur, car sous la surface de l'argument ethnographique ou commercial, se trouve la motivation la plus légitime: faire entendre au spectateur, comme en deçà des mots, la musicalité d'une autre langue et le grain de la voix qui s'y rattache ${ }^{6}$. Sous prétexte que le film joue sur la «musicalité de la langue», il ne faudrait cependant pas conclure à une pure détermination exotique. En place du caractère "étrange» ou «exogène" de la langue, l'interpénétration de la langue performée et du geste dansé participe de la cohérence de l'expérience proposée par le film: il ne s'agit pas d'étonner le spectateur en lui présentant le spectacle d'un monde inconnu, mais de l'inviter à faire l'expérience d'un enchantement. La nature participative de la culture enchantée entraîne donc le spectateur; à son tour, elle l'enveloppe, faisant de l'expérience spectatorielle une épreuve des rythmes du corps, mélangeant langue et corporalité. Ce qui s'entend en effet dans une langue parlée dont on ne saisit pas la signification, c'est d'abord la texture de la voix et, avec elle, sa physionomie et ses effets somatiques. C'est pourquoi on ne saurait tolérer de voir divisés, au sein de la visée performative du film, la langue et le geste, le mot et le corps, la nature sémiotique de l'œuvre et son contenu kinesthésique.

Dès l'entrée en matière du film, des enfants célèbrent l'approche du carnaval sur un fond de percussions dont l'intensité le dispute à la profusion des couleurs. Dans le port, les marchands font danser leurs produits. L'image est saturée par le son: les objets bigarrés des étals se mélangent aux bruits des sirènes, aux chants et aux percussions dont il est impossible de distinguer le caractère intra ou extradiégétique. C'est que le monde est luimême sous l'emprise de la liesse des corps. La dimension carnavalesque teinte dès lors chaque moment de l'existence. Car non seulement, d'un point de vue diégétique, les personnages attendent fébrilement le début de la fête et en célèbrent même à 
l'avance l'avènement par de multiples répétitions, mais leurs attitudes semblent entièrement déterminées par elle. Les corps sont indiscernables de la danse qui les mène en commun. Le carnaval est le fondement de la communauté et transfigure jusqu'au paysage. Ainsi, le film fabrique par condensation des images carnavalesques, célébrant un Brésil qui n'existe nulle part, mais qui sommeille en partie dans l'imaginaire européen, en partie dans l'imaginaire brésilien, quoique autrement: si le carnaval offre à l'imaginaire européen un visage exotique, il déploie dans l'imaginaire brésilien la force d'une extraordinaire et irréelle confusion des possibles. S'il y a une vérité dans ce cinéma, elle se tient là, au carrefour des cultures.

Dans les premières minutes du film, la lumière solaire éclaire les hauteurs sublimes d'un ghetto : les Noirs de Rio, qui sont les plus pauvres des Brésiliens, surplombent néanmoins la ville, ne ressentant jamais la fatigue d'avoir à grimper, fréquentant au plus près le ciel sans tache que le cerf-volant d'un enfant parcourt. Le monde enchanté situe le quotidien des simples à une altitude olympienne ${ }^{7}$. L'immensité du ciel et l'immensité de la mer se touchent dans le geste du simple musicien. Au-delà de l'idéalisation suggérée par Camus (on sait bien qu'à Rio les ghettos n'accueillent pas les dieux), le film assume pleinement son caractère carnavalesque. On se rappellera la lecture faite par Mikhaïl Bakhtine du carnaval médiéval : le renversement du "haut» et du "bas», des sphères les plus nobles et sacrées de la société et de celles communes et profanes, serait la fonction centrale du carnaval (Bakhtine 1970). Dans le carnaval de Camus, le dieu Soleil est incarné par un jeune chauffeur de tramway passionné de musique. Mais même en costume d'astre, Orfeu ne perd jamais le fil quotidien de sa condition.

Si Bakhtine pensait le carnaval selon les termes d'une «rupture» temporaire et ludique par rapport à un ordre social hautement réglé (ce en quoi il produit son propre chronotope), le carnaval d'Orfeu traverse entièrement l'existence et transforme le «renversement» dont parle Bakhtine en une interpénétration du haut et du bas. Le monde des dieux est celui des hommes; la prodigalité et le sacré trouvent leur source dans la simplicité d'une existence éphémère. Aussi, le rire grotesque qui 
caractérise le carnaval décrit par Bakhtine le cède-t-il chez Camus au plaisir, à ce jeu corporel entre l'extase et la fusion avec l'autre. Absent du carnaval décrit par Bakhtine, Éros déploie ici tous ses charmes. Au-delà de ce qu'il symbolise en ses diverses fonctions et parties, et au-delà de ce qu'il transgresse par le geste, le corps carnavalesque est d'abord cinétique et se fond dans le mouvement général de la liesse.

C'est faire valoir cet aspect que d'insister sur la danse et la musique. La nature participative de la fête se traduit d'abord par une "communion affective", qui précède toute figuration âne figurant le roi au Moyen Âge, fou occupant le trône, simple d'esprit gardien du sceptre. Aussi, dans le film de Camus, malgré l'apparat des costumes et des perruques, outre l'appropriation par le peuple des signes distinctifs de l'élite, c'est le vertige des couleurs, l'heureux tintamarre et la performance enjouée des danseurs qui lient indissociablement l'action à une participation émotionnelle, une sumpatheia commune à toute culture orale. C'est là l'une des formes de visibilité des arts que Jacques Rancière (2000, p. 15-16) appelle "le mouvement propre des corps communautaires" et qu'il associe à l'une des formes d'art décrites par Platon, soit la «forme chorégraphique de la communauté qui chante et danse sa propre unité».

À la fin des années 1950, en pleine guerre d'Algérie, les Français sont coupés de toute sumpatheia. Le public auquel s'adresse le film est depuis longtemps plongé dans le "désenchantement du monde ${ }^{8}$ ». En transposant l'histoire d'Orphée dans un contexte "neuf» - sur le territoire le plus énigmatique de l'Amérique latine - Camus brise le cercle infernal des bourreaux et des victimes. Aussi naïf que son film puisse paraître, il permet une sortie momentanée de l'Histoire au profit d'une mémoire ancienne, anté-historique: le mythe n'est pas un prétexte à relire l'histoire ni à se distraire d'elle; il œuvre plutôt à sa propre exhumation, à constituer le milieu propre d'une culture où la communion affective devient effective. Aussi la narrativité prend-elle dans le film la forme de l'incantation. Comme le précisait Jean-Pierre Vernant dans son livre Mythe et Société (1974, p. 199), au sujet de la culture orale antique, "si le verbe est orienté vers le plaisir, c'est qu'il agit sur l'auditeur à la 
façon d'une incantation ». À l'opposé du texte historique et de sa chronologie, l'oralité ouvre l'espace commun du plaisir et du corps; elle soulève la force d'un appel.

\section{La traversée médiumatique et la force de l'appel}

Dans son célèbre ouvrage consacré au principe espérance, Ernst Bloch distingue, à l'origine de la musique, d'une part, l'accompagnement magique du cri humain par des percussions, et, d'autre part, l'usage de la flûte de pan qui, sur le modèle du chant, se fixe sur une hauteur tonale et produit une échelle sonore. Instrument de l'enchantement amoureux, la flûte, dont le son est "censé parvenir aux oreilles de la femme aimée, aussi éloignée qu'elle fût", propose un "divertissement simple et nostalgique ". Les débuts de la musique représentent donc, selon lui, un "appel lancé à l'adresse de ce qui manque». Plus fondamentalement encore: "il est impossible de ne pas percevoir un appel dans le chant» (Bloch 1991, p. 174-175).

La parenté est frappante entre le mythe d'Orphée et celui de la naissance de la flûte en Arcadie. Le chant d'Orphée, selon différentes versions du mythe, permet de traverser les domaines de l'existence et rivalise avec celui des sirènes. Il abolit la frontière entre la matière et l'âme, entre la vie et la mort. Celui qui connaît les secrets des dieux peut envoûter les arbres, les plantes et les fauves; il sait adoucir les hommes. La figure d'Orphée incarne l'émergence d'un langage humain depuis un monde doté de sensibilité. La version de Camus s'attache à l'Eurydice de la basse Antiquité, poursuivie et tuée par un agresseur. Dans les enfers, Orphée charme les créatures infernales et obtient de revenir avec sa bien-aimée parmi les vivants à condition que, sur le chemin du retour, il ne se retourne pas pour la regarder. Il transgresse cette règle et perd Eurydice pour toujours. Ainsi, l'histoire d'Orphée vient clore l'intrigue du monde qu'il avait cru délier en rompant la frontière de la mort, mais, ce faisant, il permet le déferlement de la parole, du chant, il ouvre le monde à la multiplicité des échos de la poiêsis.

Le mythe de l'invention de la musique par Pan recoupe celui d'Orphée: courant après les nymphes, Pan s'éprend de l'hamadryade Syrinx qui, métamorphosée en roseau, lui échappe en 
traversant un cours d'eau. Le souffle du vent produit des sons enchanteurs en s'insinuant dans le roseau que Pan découpe en morceaux de diverses longueurs qu'il relie ensuite avec de la cire. Jouant de son nouvel instrument, l'amoureux se plaint et se console:

But utopique et riche de contradictions: ce jeu de flûte n'est-il pas en effet présence de ce qui a disparu? Ce qui se situe de l'autre côté de la frontière est saisi dans une plainte, regagné dans une consolation. La nymphe disparue survit sous forme de son, en lui elle se pare, s'apprête, fait retentir son absence (Bloch 1991, p. 176).

Cette dimension utopique de la musique, dont le chant et la flûte seraient les porteurs consacrés, j'aimerais en revoir la signification dans le contexte de la reprise du mythe d'Orphée par Camus. Bloch distingue la musique, véritable «rêve-souhait sonore", de la percussion, art magique de la transe. En transposant le mythe dans un Brésil carnavalesque et idéalisé, le film joint les deux pôles séparés par Bloch. D’une part, le chant et la guitare reprennent en quelque sorte l'héritage utopique de la flûte, à hauteur d'homme; ils s'adressent à la femme aimée que la mort arrache à la vie, non sans en appeler au recommencement des jours. D'autre part, le film plonge l'auditeur dans la transe par ses rythmes, tant sonores que visuels; au-delà du thème orphique, il convertit son propre dispositif en une expérience chamanique de l'incantation. Le film produit un effet magique que Bloch voulait voir dissocié de l'appel chanté, tandis que le souhait mélodique d'un amoureux épouse l'exubérance de l'incantation collective. Aussi, la lecture "européenne" de la naissance de la musique, selon laquelle celle-ci a dû d'abord s'émanciper de la percussion, est-elle remise en question dans le transfert vers la culture hybride du Brésil. Alliée au chant et à la guitare, la percussion - les battements de tambours, crécelles, sifflements — se fait "musique». Comme peut le faire, selon Bloch, le son de la flûte, la transe conduit à l'enchantement, car en ce monde, la magie et le chant se croisent indistinctement.

Tant la mise en abyme du film que son moment paroxystique se concentrent dans cette scène extatique de chamanisme: revenant bredouille du "bureau des disparus " où il a cherché à 
retrouver Eurydice, Orfeu est amené auprès d'un sorcier qui sait invoquer les esprits. Le récit pastoral de l'amoureux éconduit par la mort semble ici au plus près de s'abolir dans le réalisme d'une expérience ethnographique: une femme entre en transe sous la conduite du sorcier, tandis que la voix d'Eurydice "apparaît", conjurant Orphée de ne pas se retourner sous peine de ne plus jamais la revoir. "Je viens vers toi », dit la voix. Se croyant trompé, l'amoureux se retourne et aperçoit, en même temps que le spectateur étonné, une vieille femme, utilisant son talent de ventriloque pour se substituer à Eurydice. Le tracé poétique du film semble près de se rompre ici — c'est là le signe de la portée initiatique, donc magique, de cette scène. Sur le plan spectatoriel, celle-ci annonce l'éventualité d'une rupture parce qu'elle fait basculer la liesse carnavalesque et poétique, sa légèreté apparente, dans la gravité tensive d'une expérience brute; si la "voix" d'Euridyce peut encore mentir, le corps de cette vieille femme ne ment pas, pas davantage que les gestes séculaires du sorcier et la jeune fille en transe. Le spectateur réintègre la sphère des sons lancinants, des plaintes et des cris, comme si le cinéma, au cour même de sa mimèsis, accomplissait ce retournement par lequel, en tant que dispositif chamanique, il fait "apparaître" le fondement de toute expérience, sa trace phénoménologique.

Avec Orfeu, le spectateur se retrouve dans le monde clos de la célébration, l'un des seuls espaces sans ouverture évoqué par le film: où sommes-nous, sinon au cœur même de l'expérience cinématographique, dans le secret d'une camera - une chambre où irradient les mondes extérieurs, monde des morts, des ancêtres, mais aussi, en l'occurrence, mondes autres qui produisent simultanément des temporalités hétérogènes? Misant sur le pouvoir du médium, le chamanisme partage les qualités intrinsèques du cinéma. À la faveur d'une rencontre entre ce qui n'est plus et ce qui est là, celui-ci propose toujours une traversée médiumatique des mondes: monde concret de la réalité des corps en monstration dont on capte le mouvement et la fugacité; monde mémoriel des traces et des empreintes lumineuses en déperdition; monde exposé des extases et monde secret des imaginaires et des virtualités; monde des ombres et des morts - comme on l'a si souvent répété. Si le chaman peut entrer en 
communication avec des entités autres qu'humaines ${ }^{9}$, le cinéma révèle le monde hétérogène des choses: grouillements sourds de la nature, durée lancinante des objets, révélations de l'inanimé qui s'anime à travers la respiration des images et des sons, souffle du temps qui passe. "La nature parle à condition que nous assurions la parole», écrit Jed Rasula (1997, p. 290) à propos de l'animisme.

L'isomorphisme pointe ici vers le caractère dynamique de l'attente. Le moment charnière de la transe est celui où se confondent l'immobilité et la mobilité du corps, lorsque le danseur tombe en état de catatonie et qu'un contact semble persister grâce à ce que d'aucuns appellent "les mouvements de l'âme" (Roseman 1997, p. 186). Pas davantage que le son, le corps chamanique n'est un corps "représenté». C'est plutôt un véritable médium, un "milieu ${ }^{10}$ " de partage entre des mondes hétérogènes. Si le cinéma offre une expérience semblable, c'est au sens où le partage s'accomplit dans le seul espace du film, entre l'empreinte d'une réalité sensible, sa reproductibilité, la singularité d'une captation et l'imaginaire. Les morts nous parlent à travers lui, mais en reprenant la voix des vivants; les choses s'extirpent de leur inertie habituelle et dévoilent grâce à lui une anima insoupçonnée.

Le mythe de l'invention de la musique, l'orphisme et le chamanisme se rejoignent donc dans le film de Camus, non par volonté de syncrétisme, mais parce que la culture enchantée y transparaît de la manière la plus forte, soit par la présence extatique de corps indéniablement portés par la musique - chant et percussion confondus. La transgression des frontières entre le vivant et la mort, d'une part, et l'enchantement au sens de transport métamorphique des sons, d'autre part, n'offrent pas que des développements thématiques au film; ils désignent les confins de toute entreprise cinématographique capable de restituer cet effet de présence dont parle Bloch à partir de ce qui a disparu.

C'est bien ce que découvre Camus dans son film: le sens même que peut avoir le cinéma en tant que médium - ses effets médiumatiques, orphiques et chamaniques. Au-delà de ce que le mythe raconte, outre le thème que développe tout récit, la 
matérialité du chant ou du film détermine, par sa fluidité et son évanescence, la force d'un appel: "Merci pour ce nouveau jour", dit Orfeu à Eurydice dont il porte le corps inerte. Il ajoute: "C'est toi qui me portes. Tu chantes, Eurydice?» puis se remet à chanter. Le chant ne peut cesser parce qu'il est toujours là, en deçà comme au-delà du temps, dans la fusion de tous les temps qui libère de la mort. "Un Orphée a existé avant moi, un autre existera après moi ", dit Orfeu aux deux enfants musiciens qui l'accompagnent et dont l'un deviendra, à la fin du film, le nouveau passeur des mondes. Il raconte à Eurydice l'histoire du mythe: une histoire qui est en train d'arriver, une vieille histoire à venir qui charme la jeune femme par sa musique. Eurydice répond à l'appel: "Je me souviens des mots que vous chantiez [...]. C'est leur musique que j'aimais.» Cette fusion des temps est d'autant plus troublante qu'elle s'intègre parfaitement au matériau filmique dont la capacité de reproduction et le dispositif de saisie du temps embrouillent en un seul effet de présence les choses du passé, celles du présent et celles à venir. Par sa vocation médiumatique, le cinéma se rapproche d'autant de l'orphisme qu'il a — je paraphrase ici Charles Segal — le pouvoir de maîtriser d'intenses passions par le secours de la forme, et le pouvoir qu'a l'intense passion d'engloutir toute forme ${ }^{11}$.

Voilà bien ce qu'expérimente explicitement Camus à travers son film : délimitée par la forme millénaire du mythe, la passion amoureuse se répète, mais la passion même de la répétition déborde à son tour d'intensité, se fait chant et percussion, emprunte de manière intempestive les voies du corps qui, dans son extase, a le pouvoir d'engloutir toute forme. La descente aux enfers offre le signal de cet engloutissement lorsque, sortant du bureau des disparus, Orfeu est invité à descendre tout en bas de l'immeuble où on le conduira au chaman. Le film présente alors en plongée le plan vertigineux d'une cage d'escalier - plan qui est certes un présage de la chute fatale qui emportera Orfeu, mais, surtout, une figure prémonitoire de cette force qui, de par sa forme même, peut engloutir toute forme. En s'engageant en enfer, Orfeu retrouvera Eurydice, mais en passant par un déferlement sans précédent de corps, par la rencontre désubjectivante de la transe chamanique. 
Aussi le mythe, au sens cette fois de l'intrigue qui nous est racontée, se résorbe-t-il dans le vortex d'une pure expansion phénoménologique: ça danse! La finale du film ne montre-t-elle pas une petite fille dansant avec des gestes qui disent justement cela: ce qui s'agite en elle n'est pas elle mais bien tout ce qui la précède et la détermine. Il suffit de voir la gestuelle de cette enfant pour retrouver le fil entier du mythe, mais aussi l'ensemble de tous les gestes qui l'ont précédée. Cette danse enfantine brise la forme narrative pour mieux la rejouer avec la spontanéité paradoxale de l'élan vital: gestes rassemblés des adultes, de la foule, des morts, des Anciens, et qui sont reproduits, paradoxalement, par ce petit corps heureux et insouciant, exprimant sa joie au bord de la falaise. La force kinesthésique et somatique de la tradition déborde ce corps mais lui confère aussi une force déroutante. Cette séquence finale ouvre entièrement l'intrigue à la continuité de l'orphisme au lieu d'en sceller le sort. La danse et le plaisir du chant se poursuivent: l'euphorie souligne la force du renouveau qui est toujours déjà l'imitation de l'ancien.

\section{La traversée entre l'Europe et les Amériques}

Dans l'imaginaire occidental, la rencontre avec le Nouveau Monde implique l'épreuve d'une distance, d'une séparation. Elle suppose l'affrontement d'une étrangeté. Cependant, cette distance est commodément sublimée grâce à l'idée selon laquelle, en voyageant aux confins de l'espace maritime, on retrouverait enfin le passé de sa propre culture: ainsi l'âge d'or survivrait quelque part dans ce Nouveau Monde, où les enfants auraient paradoxalement les traits des Anciens. Ce cercle formidable dans lequel entreraient les premiers hommes, les habitants de la Terra Nova et les colonisateurs européens, produit une mémoire. Il engendre, pour les uns, des retrouvailles aussi inespérées que violentes; pour les autres, le commencement de l'effacement. Tout passage de l'Europe aux Amériques et des Amériques à l'Europe est lié par cet héritage qui constitue donc l'arrière-fond du travail de Camus. La mémoire est à la fois ce qui se construit dans ce passage et ce qui s'oblitère, transformant la géographie en archéologie, le voyage en quête du souvenir — bizarrement, le souvenir de ce qui est à être davantage que de ce qui fut. 
Aussi la transposition du mythe d'Orphée dans un Brésil contemporain relève-t-elle de cette mémoire et de cette utopie. Le film exhume le mythe et se l'approprie dans la double mire que constituent le travail de ses artisans et le territoire. Le cinéaste semble en effet retrouver l'origine même du mythe. Orphée appartient depuis toujours au visage d'un acteur brésilien. Camus croit revêtir lui-même les oripeaux orphiques: n'assure-t-il pas le passage d'un monde à un autre, de l'Antiquité occidentale au Nouveau Monde, comme n'ont cessé de le faire les premiers explorateurs des Amériques, croyant retrouver dans la jeunesse d'un continent les traces des plus anciennes civilisations? L'imaginaire européen trouve dans l'éloignement ses propres sources. Mais en retour, il finit par s'absorber lui-même dans le territoire qu'il franchit et par quitter le regard de "l'étranger" pour offrir au muthos la possibilité de se renouveler dans le passage d'une culture à une autre. C'est là un pas que ne franchissent pas les explorateurs du Nouveau Monde - loin de là -, mais que permet de franchir le médium filmique, si tant est que les créateurs d'un film soient dans des dispositions favorables. Or, sous la couche d'exotisme et d'idéalisation qui recouvre le film de Camus, se laissent justement apercevoir ces dispositions.

À l'instar de Cocteau (Orphée, 1950), Camus transpose le mythe orphique dans la modernité. Alors que le premier plonge le spectateur dans la vie nocturne et monochrome des poètes parisiens, confinant son héros solitaire à l'onirisme et à la mélancolie, Camus privilégie les forces colorées du jour à celles de la nuit - lesquelles se rencontrent merveilleusement dans l'exultation collective de la danse, du chant et du carnaval: personne ne dort, tous participent d'un cycle dont la vie et la mort dessinent ensemble la trajectoire. Contrairement à la version parisienne qui donne à la mort les traits d'une ténébreuse jeune femme, ici, la mort ne séduit pas Orfeu; elle n'est jamais attirante en elle-même, et elle se présente sous les traits les plus banals: une silhouette noire grossièrement maculée de blanc, tel le squelette des fêtes médiévales que chacun prend pour un déguisement, et qui poursuit Eurydice à travers la foule. Le principe d'envoûtement ne vient pas de la mort, mais d'un 
amour juvénile et neuf. Tandis que Cocteau pousse l'orphisme dans les retranchements coupables d'une existentialité conjugale où l'amour est déjà consumé, Camus exalte la spontanéité de la rencontre amoureuse qui prend la tournure de l'émulation: Eurydice et Orfeu dansent ensemble en explorant leurs propres limites. Chacun pousse l'autre à se dépasser. À la vision policière et individualiste de Cocteau, Camus oppose la force collective du carnaval et l'érotisme brut de la danse.

Les neuf années qui séparent les deux films sont déterminantes. Autant le film de Cocteau s'inscrit dans l'immédiate après-guerre et participe encore de l'idéalisation narcissique de l'artiste, autant celui de Camus profite de cette recherche "d'authenticité» inaugurée par le cinéma direct et, en particulier, par la Nouvelle Vague. Si Cocteau confere à Orphée une dimension statuaire dont il se croira plus tard lui-même investi (voir Le Testament d'Orphée, 1960), Camus cherche par tous les moyens à briser le statut pétrifié du mythe en le déplaçant au Brésil. Le déplacement a donc, comme on l'a laissé entendre plus tôt, une double incidence: dans un premier temps, il permet au mythe de retourner à ses sources anciennes, plus près d'une culture enchantée; dans un deuxième temps, il en renouvelle la facture en se laissant pénétrer par une autre culture. Du coup, Camus découvre deux aspects inédits du mythe: sa valeur cinématographique (ou la fonction médiumatique et chamanique du cinéma) et sa force d'hybridation (dans le carnaval). Au cœur de cette double découverte agissent les corps et les gestes filmés, cette plénitude vitale qui déborde le cadre narratif du film et confère aux acteurs-danseurs et à la musique la force d'une vérité dont il serait réducteur de dire qu'elle n'est qu'ethnographique. Cette force déploie un monde poétique au sens le plus ancien du terme: un monde envisagé dans sa fabrication originaire.

Dans Orfeu Negro, les corps parlent bien au-delà de l'auctorialité de Camus et de l'autorité narrative du mythe d'Orphée. Leurs "mémoires corporelles» - la mémoire de leurs gestes parlent à travers eux et franchissent les limites de "l'œuvre d'art", peut-être même celles d'une "poiêsis collective", pour atteindre ce déferlement de la "vox» humaine, cette ouverture 
du conte à l'utopie à laquelle Walter Benjamin est si sensible et que tente de décrire Ernst Bloch sous les traits de l'espérance ${ }^{12}$. Cela se confirme de manière figurative et sans doute un peu naïve par la présence d'une image: celle de l'oiseau en cage, qui revient à plusieurs reprises dans le film et qui est doublée par celle du cerf-volant. Qu'on se souvienne simplement de cette très belle séquence du sommeil qui ne vient pas: la barrière de bambou qui sépare et unit les deux amoureux, Eurydice et Orfeu; la porte ouverte par le souffle de la nuit et la présence inusitée d'un oiseau en liberté au chevet de la jeune femme. Ces motifs icariens, tout en étant intrinsèquement liés à la nature "solaire» d'Orphée, révèlent avant tout la confiance que prête Camus à toute figuration du voyage ou de l'envol. Quelque chose s'exprime ici comme un désir de sortir de soi, une volonté paradoxalement désubjectivante et utopiste.

Le résultat est frappant: Camus trouve, dans la collaboration avec les artistes, musiciens et danseurs brésiliens, ce qui demeurait toujours en reste dans l'interprétation moderne du mythe, à savoir le caractère enchanté de la culture qui le porte, cette fusion entre l'esprit de la musique, le souffle de la narration et la puissance somatique des percussions qui transportent au-delà des frontières. Du coup, le lien viscéral qui s'établit entre la musique et l'image filmique libère les possibilités du médium autant que celles du mythe et l'affranchit des limites du langage ${ }^{13}$. C'est parce que le son ne connaît pas de dichotomie spatiale entre intériorité et extériorité qu'il permet de «voyager».

Malgré son indéniable caractère fictionnel, Orfeu Negro donne à voir avant tout le souffle — corporel et musical — qui transporte et emporte la vie au-delà de l'achoppement transitoire qu'est la mort. Ce n'est plus l'héritage grec qui passe dans le film, et avec lui la muséologie européenne, mais le caractère inédit d'un mythe qui s'évapore et devient pure présence donnée à voir. Eurydice est d'autant plus vraie qu'elle apparaît comme pour la première fois, non pas contre toute tradition ${ }^{14}$, mais sous les traits oubliés de son visage millénaire, sous sa visagéité la plus ancienne et que seules l'effusion et l'intensité corporelles de la danse peuvent rendre, quand elles sont captées et reproduites 
par une image sonore. Car l'image filmique, contrairement à la performance vivante de la danse, ne cesse de rendre présent ce qu'elle tient éloigné, de faire apparaître ce qu'elle soustrait à la vue; elle rend présente la perte en elle-même et donne corps à l'absence, elle confond la jeunesse et la spectralité.

Le déplacement du mythe au Brésil est donc crucial. Certes, il n'efface en rien les dispositions "européennes» de l'aventure: le désir de voir dans l'Autre le miroir d'une origine de soi afin de mettre au jour la part d'altérité en soi est toujours présent. Toutefois, le déplacement permet justement, à un autre niveau, de contourner le problème de la subjectivation et de l'objectivation, si oppressant dans la modernité, notamment dans le milieu du cinéma au sein duquel œuvre Camus. Rappelons simplement les débats autour de la modernité du cinéma et qui ont pour nœud gordien la relation entre la subjectivité des opérateurs et l'objectivité de la technologie, entre la part d'imaginaire et le réalisme du médium. C'est tout cela que relance à nouveau l'émergence du cinéma direct et de la Nouvelle Vague, au moment où Camus tourne son film. Le voyage au Brésil lui permettra sans doute de joindre les deux extrémités du débat en montrant que le mythe niche dans le corps des êtres et que ce corps joue sa propre musique, à la fois soumis et souverain.

Si l'exigence de vérité coöncide avec la forme idéalisante choisie par Camus pour son film, si elle produit un effet qui est le contraire de la distanciation ethnographique ou du caractère subjectif de l'œuvre, c'est parce que le mythe lui-même contient sa propre force de désubjectivation et de dessaisissement. L'exultation poétique advient d'emblée, dans le geste de la répétition.

Université du Québec à Montréal

\section{NOTES}

1. La rédaction de cet article a été rendue possible grâce à une subvention de recherche octroyée par le FQRSC dans le cadre d'un projet intitulé "L'intermédialité de l'expérience». 
2. Coproduction de la France et du Brésil (Dispatfilm, Paris, et Tupan-Filmes, São Paulo), 1959.

3. Voir, par exemple, Clifford 1996. Au cinéma, le travail des Robert Flaherty, Joris Ivens et Jean Rouch est sans cesse, comme on le sait, confronté à ces problèmes. Voir aussi Niney 2002 et Marsolais 1974.

4. Au sujet d'Orphée en tant que "franchisseur de frontières ", voir Bloch 1991 (p. 176).

5. La bande sonore d'Orfeu Negro remplit une fonction opposée à celle qu'Adorno attribue à la musique de film dans son célèbre essai Musique de cinéma. Adorno s'intéresse surtout à l'opposition entre musique traditionnelle et musique moderne, la seconde présentant selon lui l'objectivité nécessaire pour révéler dialectiquement le drame, ce qu'interdisaient les automatismes, les répétitions et le souci de symétrie, caractéristiques de la musique traditionnelle. Chez Camus, rien de tel. Malgré le caractère novateur de la musique de Jobim, celle-ci revisite une tradition musicale déjà bien implantée et met en valeur la trame mille fois rejouée du carnaval. En cela, elle ne fournit aucune objectivité au sens critique, tel que l'entend Adorno, mais se soumet plutôt au pouvoir d'objectivation de l'image filmique en tant que trace d'une expérience donnée, en l'occurrence la danse.

6. J'emprunte bien sûr le terme à Roland Barthes (1982). L'écoute d'une langue étrangère qu'on ne connaît pas fait d'autant mieux ressortir le grain singulier de la voix que l'auditeur en ignore la sémantique et en néglige ainsi la portée des signes à la faveur de la pure perception.

7. Cette rencontre entre le monde de l'humble et celui des dieux est centrale dans la culture orale traditionnelle, en particulier dans les contes où le simple pêcheur ou le paysan se mesure à l'adresse des princes pour leur ravir un pouvoir dont ils n'ont su faire eux-mêmes bon usage. Le thème millénaire du dévoilement n'est pas étranger à cette rencontre; pensons à Ulysse qui, à son retour à Ithaque sous les traits d'un mendiant, subit l'humiliation des princes avant de les massacrer et de leur ravir un trône qui lui revient.

8. L'expression remonte, comme on le sait, aux travaux de Max Weber.

9. Voir Harvey 2003.

10. En cela le corps chamanique est régi par ce que les Anciens appelaient les "humeurs", qui déterminent la condition du mélancolique.

11. Voir Charles Segal, Orpheus: The Myth of the Poet (1989), cité par Rasula (1997).

12. Je fais référence à la célèbre étude de Walter Benjamin sur le conteur traditionnel ("Le narrateur», 1987) et aux travaux d'Ernst Bloch consacrés au conte, qu'il rattache à son principe espérance ("De meilleurs châteaux en Espagne: ceux de la foire et du cirque, du conte et du roman populaire», 1976).

13. Je paraphrase ici Paul Zumthor, spécialiste de la culture orale, qui écrit dans $L a$ Lettre et la Voix que la voix "franchit les limites du langage». En cela, soutient-il, elle collabore au désir de s'évader (Zumthor 1987, p. 186-187).

14. Il ne s'agit pas de "défamiliarisation » ou de singularisation, comme on pourrait le penser en se référant à ces notions formulées par les formalistes russes: "voir comme pour la première fois» était en effet la formule consacrée par ces procédés. Il s'agit plutôt de rompre avec l'habitude de perception imposée par la tradition. Ce n'est plus le cas ici, car la dichotomie entre tradition et modernité ne tient plus. Voir Chklovski 1975. 


\section{RÉFÉRENCES BIBLIOGRAPHIQUES}

Adorno 1972: Theodor W. Adorno, Musique de cinéma [1969], Paris, L’Arche, 1972. Bakhtine 1970 : Mikhaïl Bakhtine, L'Euvre de François Rabelais et la culture populaire au Moyen Âge et sous la Renaissance, Paris, Gallimard, 1970.

Barthes 1982 : Roland Barthes, L'Obvie et l'Obtus, Paris, Seuil, 1982.

Benjamin 1987 : Walter Benjamin, "Le narrateur", Rastelli raconte..., Paris, Seuil, 1987, p. 145-178.

Bloch 1976: Ernst Bloch, «De meilleurs châteaux en Espagne: ceux de la foire et du cirque, du conte et du roman populaire», Le Principe espérance I, Paris, Gallimard, 1976, p. 420-437.

Bloch 1991: Ernst Bloch, Le Principe espérance III. Les images souhaits de l'Instant exaucé, Paris, Gallimard, 1991.

Chklovski 1965: Victor Chklovski, «L'art comme procédé» [1917], Théorie de la littérature, Paris, Seuil, 1965, p. 76-97.

Clifford 1996 : James Clifford, Malaise dans la culture. L'ethnographie, la littérature et l'art au XX' siècle, Paris, École Nationale Supérieure des Beaux-Arts, 1996.

Harvey 2003: Graham Harvey (dir.), Shamanism: A Reader, London/New York, Routledge, 2003.

Marsolais 1974: Gilles Marsolais, L’Aventure du cinéma direct, Paris, Seghers, 1974.

Niney 2002: François Niney, L'Épreuve du réel à l'écran. Essai sur le principe de réalité documentaire, Bruxelles, Éditions de Boeck Université, 2002.

Rancière 2000 : Jacques Rancière, Le Partage du sensible. Esthétique et politique, Paris, La Fabrique, 2000.

Rasula 1997 : Jed Rasula, «Poetry's Voice-over», dans Adalaide Morris (dir.), Sound State: Innovative Poetics and Acoustical Technologies, Chapel Hill, University of North Carolina Press, 1997.

Roseman 1997 : Marina Roseman, "Remembering to Forget. The Aesthetics of Longing", dans Adalaide Morris (dir.), Sound State: Innovative Poetics and Acoustical Technologies, Chapel Hill, University of North Carolina Press, 1997.

Vernant 1974 : Jean-Pierre Vernant, Mythe et Société, Paris, François Maspero, 1974.

Zumthor 1987 : Paul Zumthor, La Lettre et la Voix, Paris, Seuil, 1987. 